\title{
Association of T-cadherin levels with the response to neoadjuvant chemotherapy in locally advanced breast cancer
}

\author{
Dedi Kong ${ }^{1}$, Mei-Hong Wang ${ }^{1}$, Jie Yang ${ }^{2}$, Liang $\mathrm{Li}^{3}$ \\ ${ }^{1}$ Department of Thyroid and Breast Surgery, Jining No.1 People's Hospital, Jiningy 272011, Shandong, People's Republic of \\ China \\ ${ }^{2}$ Department of Pathology, Jining No.1 People's Hospital, Jiningy 272011, Shandong, People's Republic of China \\ ${ }^{3}$ Department of Pharmacy, Jining No.1 People's Hospital, Jiningy 272011, Shandong, People's Republic of China
}

Correspondence to: Dedi Kong, email: kangtailu@yahoo.com

Keywords: T-cadherin, neoadjuvant chemotherapy, locally advanced breast cancer

Received: September 14, 2016

Accepted: January 07, 2017

Published: January 13, 2017

\section{ABSTRACT}

Purpose: To examine the association of T-cadherin with pathologic complete response (PCR) after neoadjuvant chemotherapy for locally advanced breast cancer.

Results: T-cadherin expression before and after neoadjuvant chemotherapy was similar $(P=0.162)$. The multivariable analysis indicated that negative T-cadherin expression was independently associated with PCR after neoadjuvant TAC chemotherapy $(P=0.001)$.

Materials and Methods: A total of 136 patients with locally advanced breast cancer received four cycles of neoadjuvant TAC chemotherapy (docetaxel + epirubicin + cyclophosphamide), followed by surgery. T-cadherin, estrogen receptor (ER), progesterone receptor (PR), HER-2, and Ki-67 were analyzed by immunohistochemistry. The association between T-cadherin expression and PCR after neoadjuvant chemotherapy was analyzed using multivariable logistic analysis.

Conclusions: Negative T-cadherin expression before and after neoadjuvant chemotherapy for locally advanced breast cancer was similar. T-cadherin could be considered an independent factor associated with the efficacy of such therapy.

\section{INTRODUCTION}

Breast cancer is a systemic disease and in its primary stage, the cancer cells can micro-metastasize to other organs via blood or lymph. Locally advanced breast cancer implies Stage III breast cancer and local recurrences [1]. In China, the number of patients with locally advanced breast cancer accounts for $20-30 \%$, which is significantly higher than that in western developed countries [2].

Neoadjuvant chemotherapy ( $\mathrm{NC}$ ) is widely used for locally advanced breast cancer. NC allows the control of the primary tumor, increases the resectability and breast-conserving rates, and decreases the rate of micrometastases, thereby improving long-term survival [3-5]. Indeed, the disease-free survival and overall survival of patients receiving pCR are improved $[6,7]$.

Nevertheless, there are some problems with the application of NC for breast cancer. Indeed, $20 \%$ of the patients with locally advanced breast cancer are not sensitive to chemotherapy and $\mathrm{NC}$ will only delay the surgery $[8,9]$. Therefore, key issues of $\mathrm{NC}$ are how to select the individuals that have the highest probability of pathologic complete response (pCR), how to predict and monitor efficacy, and how to accurately evaluate efficacy. pCR is the gold standard for evaluating chemotherapeutic effects and can partially predict the prognosis $[10,11] . \quad \mathrm{pCR}$ correlates with immunohistochemical markers of breast cancer and these markers could be used to individualize the therapy. Therefore, many studies have reported factors predicting $\mathrm{NC}$ efficacy, including estrogen receptor (ER), progesterone receptor (PR), p53, C-erbB-2 (or HER-2), and Ki-67, among others [12-15], but the sensitivity of these factors is poor. Additional and better markers are necessary to predict the efficacy of NC.

A recent study has indicated that T-cadherin (also known as $\mathrm{H}$-cadherin and cadherin-CDH13) is associated with malignant tumors [16-19]. Down-regulation of T-cadherin is associated with an increased risk of malignancy development $[20,21]$. A previous study by our group showed that the occurrence of T-cadherin negativity in locally advanced breast cancer $(23.2 \%)$ was 
significantly higher than that in Stage I-II breast cancers $(6.0 \%, P=0.001)$ [22], but the difference in T-cadherin expression before and after NC in locally advanced breast cancer as well as its potential association with prognosis after NC remain unclear.

Therefore, the present study used immunohistochemistry to analyze T-cadherin expression before and after NC in locally advanced breast cancer samples, and to examine the association of T-cadherin expression with $\mathrm{pCR}$ after $\mathrm{NC}$.

\section{RESULTS}

\section{Characteristics of the patients}

All patients were women of 30-67 years of age (mean, 48.3 years). They had measurable tumor foci with diameter $\geq 3 \mathrm{~cm}$ as detected by mammography or B-mode ultrasound. The detailed clinical and pathological data are shown in Table 1.

\section{T-cadherin expression}

T-cadherin expression before and after $\mathrm{NC}$ was detected by immunohistochemistry (Figure 1). Before NC, there were $92 \mathrm{~T}$-cadherin-positive cases and 44 negative cases. After NC, there were 103 positive cases and 33 negative cases $(P=0.162$, Wilcoxon rank-sum test $)$ (Table 2). There were no significant differences in ER $(P=0.139)$, PR $(P=0.798)$, and HER-2 $(P=0.781)$ before and after NC. However, Ki67 was significantly decreased after NC $(P=0.001)$ (Table 1).

\section{Pathologic response after NC}

There were 26 cases of pCR, 80 of PPR, and 30 of PSD according to the pathological efficacy grading standard. The pCR rate was $19.1 \%$.

Univariate analyses showed that $\mathrm{pCR}$ was more frequent in patients with negative T-cadherin $(P=0.001)$, negative $\operatorname{ER}(P=0.001)$, negative PR $(P=0.001)$, and positive $\operatorname{Ki} 67(P=0.028)$ (Table 1$)$. Multivariable logistic regression analysis showed that negative T-cadherin $(P<0.001)$ and negative PR $(P=0.006)$ were independently associated with $\mathrm{pCR}(P=0.001, P=0.046$, $P=0.007$, and $P=0.007$, respectively) (Table 3 ).

The ROC analyses showed that ER negativity had $40.0 \%$ sensitivity, $24.3 \%$ specificity, and $27.2 \%$ accuracy for pCR. PR negativity had $36.0 \%$ sensitivity, $26.1 \%$ specificity, and $27.9 \%$ accuracy for pCR. Ki67 positivity had $84.0 \%$ sensitivity, $15.3 \%$ specificity, and $27.9 \%$ accuracy for pCR. Lastly, T-cadherin negativity had $24.0 \%$ sensitivity, $20.7 \%$ specificity, and $21.3 \%$ accuracy for pCR (Table 4).

\section{DISCUSSION}

A recent study has indicated that T-cadherin is associated with malignant tumors [16-19] such as melanoma [23, 24], ovarian cancer [25], gastric cancer

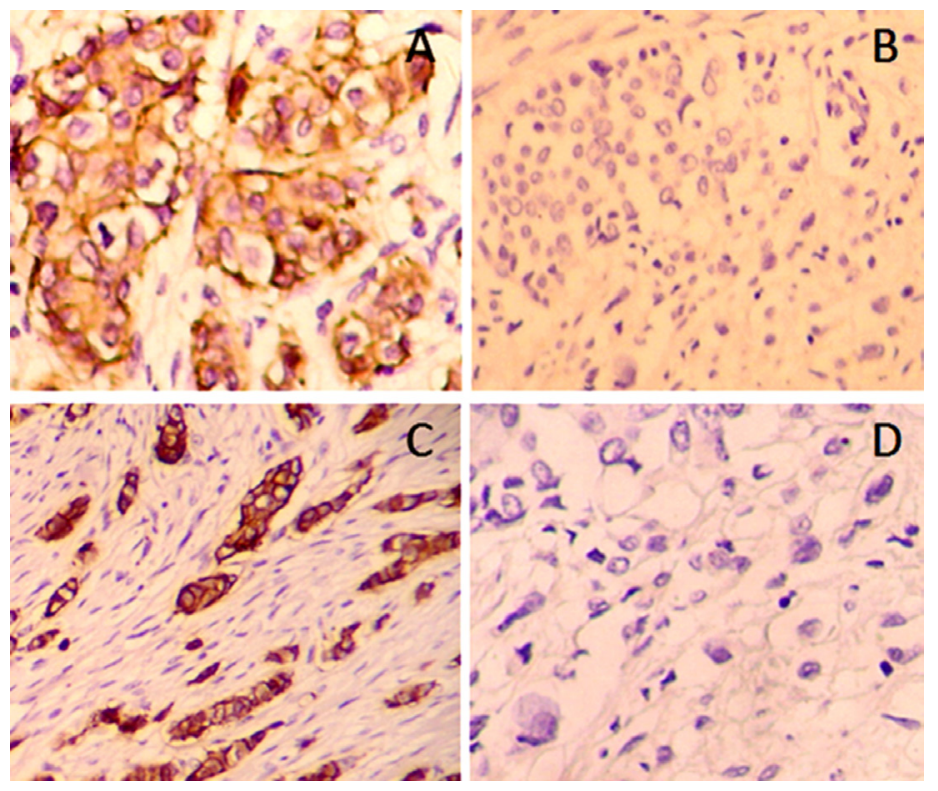

Figure 1: Expression of T-cadherin in histological samples was detected using immunochemistry. Images showed representative samples with positive $(\mathbf{A}, \mathbf{C})$ and negative $(\mathbf{B}, \mathbf{D})$ T-Cadherin expression, either before $(\mathrm{A}, \mathrm{B})$ or after $(\mathrm{C}, \mathrm{D})$ adjuvant chemotherapy $(\times 200)$. 
Table 1: Associations between clinicopathological parameters before NC with pCR

\begin{tabular}{|c|c|c|c|c|}
\hline Parameters & $n$ & pCR & non-pCR & $P$-value \\
\hline \multicolumn{5}{|l|}{ Age (years) } \\
\hline$<50$ & 59 & 9 & 50 & \multirow{2}{*}{0.316} \\
\hline$\geq 50$ & 77 & 17 & 60 & \\
\hline \multicolumn{5}{|l|}{ Tumor size $(\mathrm{cm})$} \\
\hline$<5$ & 43 & 10 & 33 & \multirow{2}{*}{0.404} \\
\hline$\geq 5$ & 93 & 16 & 77 & \\
\hline \multicolumn{5}{|l|}{ Lymph node status } \\
\hline Positive & 123 & 23 & 100 & \multirow{2}{*}{0.703} \\
\hline Negative & 13 & 3 & 10 & \\
\hline \multicolumn{5}{|l|}{ Menopausal status } \\
\hline No & 84 & 14 & 70 & \multirow{2}{*}{0.356} \\
\hline Yes & 52 & 12 & 40 & \\
\hline \multicolumn{5}{|l|}{ ER } \\
\hline Positive & 92 & 8 & 84 & \multirow{2}{*}{0.001} \\
\hline Negative & 44 & 18 & 26 & \\
\hline \multicolumn{5}{|l|}{ PR } \\
\hline Positive & 91 & 9 & 82 & \multirow{2}{*}{0.001} \\
\hline Negative & 45 & 17 & 28 & \\
\hline \multicolumn{5}{|l|}{ HER2 } \\
\hline Positive & 36 & 9 & 27 & \multirow{2}{*}{0.295} \\
\hline Negative & 100 & 17 & 83 & \\
\hline \multicolumn{5}{|l|}{ Ki-67 } \\
\hline Positive & 110 & 25 & 85 & \multirow{2}{*}{0.028} \\
\hline Negative & 26 & 1 & 25 & \\
\hline \multicolumn{5}{|l|}{ T-cadherin } \\
\hline Positive & 94 & 7 & 87 & \multirow{2}{*}{0.001} \\
\hline Negative & 42 & 19 & 23 & \\
\hline
\end{tabular}

Table 2: T-cadherin expression in locally advanced breast cancer tissues before and after NC

\begin{tabular}{|c|c|c|c|c|c|c|c|c|c|c|}
\hline & \multicolumn{2}{|c|}{ ER } & \multicolumn{2}{|c|}{ PR } & \multicolumn{2}{|c|}{ Her-2 } & \multicolumn{2}{|c|}{ Ki-67 } & \multicolumn{2}{|c|}{ T-cadherin } \\
\hline & + & - & + & - & + & - & + & - & + & - \\
\hline Before NC & 92 & 44 & 91 & 45 & 36 & 100 & 110 & 26 & 94 & 42 \\
\hline After NC & 103 & 33 & 89 & 47 & 34 & 102 & 64 & 62 & 83 & 53 \\
\hline $\mathrm{P}$ & \multicolumn{2}{|c|}{0.139} & \multicolumn{2}{|c|}{0.798} & \multicolumn{2}{|c|}{0.781} & \multicolumn{2}{|c|}{0.001} & \multicolumn{2}{|c|}{0.162} \\
\hline
\end{tabular}

[26, 27], lung cancer, and breast cancer [28-30]. Positive expression of T-cadherin can inhibit cell proliferation and invasion, increase the sensitivity to apoptosis, and decrease tumor growth, suggesting that down-regulation of T-cadherin is associated with an increased risk of cancer $[20,21]$. Its high expression can inhibit cell growth and invasion induced by the epidermal growth factor [31].
A previous study by our group showed that the occurrence of T-cadherin negativity in locally advanced breast cancer $(23.2 \%)$ was significantly higher than that in Stage I-II breast cancers $(6.0 \%, P=0.001)$ [22].

The association between T-cadherin expression and the efficacy of NC for locally advanced breast cancer NC remains unclear. It has been reported that T-cadherin can 
Table 3: Multivariable analysis of the factors associated with pCR

\begin{tabular}{lccccc}
\hline & B & P-value & OR & Lower & Upper \\
\hline ER & -1.164 & 0.081 & 0.312 & 0.084 & 1.154 \\
PR & -2.081 & 0.006 & 0.125 & 0.028 & 0.549 \\
Ki67 & 0.729 & 0.362 & 2.074 & 0.433 & 9.936 \\
T-cadherin & -3.503 & 0.000 & 0.030 & 0.007 & 0.132 \\
\hline
\end{tabular}

Abbreviations: B, partial regression coefficient; SE, standard error; RR, relative risk; CI, confidence interval.

Table 4: ROC analysis of the accuracy of factors associated with pCR

\begin{tabular}{lccccc}
\hline & Sensitivity (\%) & Specificity (\%) & PPV (\%) & NPV (\%) & Accuracy (\%) \\
\hline ER & 40.00 & 24.32 & 10.64 & 64.29 & 27.21 \\
PR & 36.00 & 26.13 & 9.89 & 64.44 & 27.94 \\
Ki67 & 84.00 & 15.32 & 18.26 & 80.95 & 27.94 \\
T-cadherin & 24.00 & 20.72 & 6.38 & 54.76 & 21.32 \\
\hline
\end{tabular}

be used as an efficacy predictive factor for $\mathrm{NC}$ of breast cancer, guiding the application of chemotherapy and avoiding E-cadherin [32]. In the present study, negative T-cadherin expression was associated with a higher rate of pCR. This is supported by a previous study that showed that patients with positive T-cadherin expression had a worse prognosis [31].

Results showed that the expression of Ki67 after $\mathrm{NC}$ was significantly decreased, which is supported by a previous study [33]. A previous study showed that ER and HER2 statuses did not change after NC [34], as observed in the present study, but PR status changed after NC [34]. In the present study, PR status did not change after $\mathrm{NC}$, but PR negativity was associated with $\mathrm{pCR}$ after NC. Another study showed that both ER and PR statuses changed after NC [35]. Discrepancies among studies could be due to the study populations, $\mathrm{NC}$ regimen, tumor stage, and ethnicity.

The present study is not without limitations. The sample size was small and from a single hospital. Only a limited panel of markers were assessed. A number of confounding factors could not be taken into consideration because the data were either not collected or not available, or because of the small sample size. The sensitivity analyses were limited by the small sample size and because each factor was analyzed alone. Algorithms of multiple factors could be explored to improve the predictive power.

\section{CONCLUSIONS}

T-cadherin was independently associated with pCR after NC for locally advanced breast cancer. It has the potential to be used as a marker for predicting the clinical efficacy of NC in these patients. Selection of more specific therapy regimens according to the expression of
T-cadherin in locally advanced breast cancer is promising, and T-cadherin could become a new therapy target.

\section{MATERIALS AND METHODS}

\section{Study subjects}

The study subjects were consecutive patients treated at the Department of Breast Surgery, Jining No. 1 People's Hospital between January 2013 and December 2014. Inclusion criteria were: 1) diagnosis of locally advanced breast cancer (Stage III) confirmed by ultrasound-guided core needle biopsy and imaging; 2) available tissue samples from before (biopsy) and after (surgery) $\mathrm{NC} ; 3$ ) no contraindication to chemotherapy and received $\mathrm{NC}$; and 4) no prior history of chemotherapy, radiotherapy, endocrine therapy, or molecular targeting therapy before chemotherapy. The exclusion criteria were: 1) inflammatory breast cancer or complicated with inflammatory breast cancer; 2) distant metastases according to ultrasound, computed tomography (CT), or bone scan; 3) did not undergo surgery; or 4) incomplete medical record. After biopsy, all patients received four cycles of TAC regimen (docetaxel + epirubicin + cyclophosphamide), followed by surgery.

The present study was approved by the ethical committee of the Jining No. 1 People's Hospital. The study was conducted in compliance to the Declaration of Helsinki and local regulations.

\section{Neoadjuvant chemotherapy and surgery}

After hospitalization, the patients signed an informed consent for the chemotherapy and received NC. The received the TAC regimen ( 4 cycles of 21 days each): 
epirubicin $70 \mathrm{mg} / \mathrm{m}^{2}$ iv on day 1 ; cyclophosphamide $500 \mathrm{mg} / \mathrm{m}^{2}$ iv on day 1 ; and docetaxel $75 \mathrm{mg} / \mathrm{m}^{2}$ iv on day 2. All patients underwent hepatorenal function, electrocardiography, and echocardiography to examine their tolerance to chemotherapy. Dexamethasone tablets were administered orally for three days before NC. In order to prevent water-sodium retention and allergy, omeprazole and ondansetron were given as support therapy (for stomach protection and anti-nausea). Based on the hemogram results after $\mathrm{NC}$, adequate $\mathrm{G}-\mathrm{CSF}$ was given to increase the white blood cells.

Breast conserving surgery (local extended resection plus axillary lymph node dissection), modified radical mastectomy, or radical mastectomy were performed according to the tumor size, location, patient's wishes, and other clinical considerations.

\section{Outcomes}

The description and grading were made according to the features described in The standard of diagnosis and treatment of breast cancer edited by the Ministry of Health of the People's Republic of China [36, 37]. The pathological remission degree was divided into three grades. 1) No pathological change (pSD): slight tissue reaction, effective chemotherapy but not sensitive. The reaction area was less than one-third of the section with more invasive carcinoma. Besides, cancer cells survived, and the lymphatic metastasis rate was high. 2) Partial pathological remission ( $\mathrm{pPR}$ ): moderate tissue reaction, moderate sensitivity to chemotherapy. The reaction area was about half of the section with invasive carcinoma and lymph node metastasis. 3) pCR: severe tissue reaction, and very sensitive to chemotherapy. Intraductal carcinoma could be observed on sections, but no invasive component, with extremely low lymph node metastasis rate.

\section{Detection of T-cadherin}

Specimens were processed within 15 minutes after surgery. Sections were stained with H\&E for histopathological diagnosis. Immunochemistry was performed to detect T-cadherin, ER, PR, HER-2, and Ki-67. All tissues were immediately fixed in $10 \%$ formalin and embedded in paraffin. The tissues were sectioned into 20 3-4- $\mu \mathrm{m}$ sections. One was stained by H\&E and 12 were used for immunohistochemistry. Mouse anti-human T-cadherin monoclonal antibody, immunohistochemistry SP kits, DAB, and PBS buffer were from Fuzhou Maixin Biotech. Co., Ltd. T-cadherin positive staining was mainly located in the cell membrane. The staining results were divided into four grades by semi-quantitative analysis [22]. Staining strength: 0 (no color), 1 (light yellow), 2 (claybank), and 3 (sepia). Stained cell percentage: $0:<20 \% ; 1: 21-50 \% ; 2: 51-75 \%$; and $3:>76 \%$. The score was calculated by the product of the stained cells rate and staining strength. The final results were divided into: 0 , negative $(-) ; 1-3$, weakly positive $(+) ; 4-6$, moderately positive $(+)$; and $7-9$, strongly positive $(+++)$. For analysis, the results were divided as negative $(0-3)$ and positive (4-12).

ER, PR, HER-2, and Ki-67 were evaluated according to the Guidelines for immunohistochemical detection of hormone receptors of the American Society of Clinical Oncology and American Society of Pathologists (ASCO/ASP) and the new standard of biological factors detection recommended by the St. Gallen International expert consensus on initial treatment for early breast cancer [38, 39].

\section{Data collection}

All pathological diagnoses were performed by two experienced pathologists. Discrepancies were ruled out by consultation with a third pathologist. Demographic and clinical data were obtained directly from the charts.

\section{Statistical analysis}

SPSS 17.0 (IBM, Armonk, NY, USA) was used to analyze the data. T-cadherin expression before and after NC was analyzed by the Wilcoxon rank-sum test. The association between T-cadherin and efficacy of NC was tested using the chi-square test. Variables associated with pCR in univariable analyses were included in the multivariable logistic regression analysis. Receiver operating characteristic (ROC) curves were used to determine the accuracy of the receptors for pCR. $P<0.05$ was defined as statistically significant.

\section{CONFLICTS OF INTEREST}

The authors declare no conflicts of interest.

\section{REFERENCES}

1. Cao ZY, He JM, Yang B, Zhang QJ. Clinical efficacy of breast-conserving surgery combined with neoadjuvant chemotherapy for locally advanced breast cancer: a report of 81 cases. Med J Chin PLA. 2015; 40:488-491.

2. Shen ZZ, Liu GY, Su FX, He PQ, Yang MT, Shi JY, Sheng Y, Zou Q, Li YF. [Neoadjuvant chemotherapy with docetaxel plus epirubicin for locally advanced breast cancer: a multi-center phase II study]. [Article in Chinese]. Zhonghua zhong liu za zhi. 2005; 27:126-128.

3. Breslin TM. Neoadjuvant chemotherapy for breast cancer: a surgeon's checklist. Breast cancer research and treatment. 2011; 127:129-131.

4. Huang O, Jiang M, Chen XS, Wu JY, Chen WG, Li YF, Shen KW. Prognostic factors of survival in pathologic incomplete response patients with locally advanced breast 
cancer after neoadjuvant chemotherapy. Cell biochemistry and biophysics. 2015; 71:1181-1190.

5. Arnaout A, Boileau JF, Brackstone M. Surgical considerations in locally advanced breast cancer patients receiving neoadjuvant chemotherapy. Current opinion in supportive and palliative care. 2014; 8:39-45.

6. Zhang GC, Zhang YF, Xu FP, Qian XK, Guo ZB, Ren CY, Yao M. Axillary lymph node status, adjusted for pathologic complete response in breast and axilla after neoadjuvant chemotherapy, predicts differential disease-free survival in breast cancer. Current oncology. 2013; 20:e180-192.

7. Kern P, Kalisch A, von Minckwitz G, Putter C, Kolberg HC, Pott D, Kurbacher C, Rezai M, Kimmig R. Neoadjuvant, anthracycline-free chemotherapy with carboplatin and docetaxel in triple-negative, early-stage breast cancer: a multicentric analysis of rates of pathologic complete response and survival. Journal of chemotherapy. 2016; 28:210-217.

8. Chen S, Huang L, Chen CM, Shao ZM. Progesterone receptor loss identifies luminal-type local advanced breast cancer with poor survival in patients who fail to achieve a pathological complete response to neoadjuvant chemotherapy. Oncotarget. 2015; 6:18174-18182. doi: 10.18632/oncotarget.4225.

9. Park K, Choi MK, Jung HH, Do IG, Lee KH, Ahn T, Kil WH, Kim SW, Lee JE, Nam SJ, Kim DH, Ahn JS, Im YH, et al. Molecular characterization of patients with pathologic complete response or early failure after neoadjuvant chemotherapy for locally advanced breast cancer using next generation sequencing and nCounter assay. Oncotarget. 2015; 6:24499-24510. doi: 10.18632/ oncotarget. 4119.

10. Guarneri V, Broglio K, Kau SW, Cristofanilli M, Buzdar AU, Valero V, Buchholz T, Meric F, Middleton L, Hortobagyi GN, Gonzalez-Angulo AM. Prognostic value of pathologic complete response after primary chemotherapy in relation to hormone receptor status and other factors. Journal of clinical oncology. 2006; 24:1037-1044.

11. Li XB, Krishnamurti U, Bhattarai S, Klimov S, Reid MD, O’Regan R, Aneja R. Biomarkers Predicting Pathologic Complete Response to Neoadjuvant Chemotherapy in Breast Cancer. American journal of clinical pathology. 2016; 145:871-878.

12. Yoshioka T, Hosoda M, Yamamoto M, Taguchi K, Hatanaka KC, Takakuwa E, Hatanaka Y, Matsuno Y, Yamashita H. Prognostic significance of pathologic complete response and Ki67 expression after neoadjuvant chemotherapy in breast cancer. Breast cancer. 2015; 22:185-191.

13. Kurozumi S, Inoue K, Takei H, Matsumoto H, Kurosumi M, Horiguchi J, Takeyoshi I, Oyama T. ER, PgR, Ki67, p27(Kip1), and histological grade as predictors of pathological complete response in patients with HER2positive breast cancer receiving neoadjuvant chemotherapy using taxanes followed by fluorouracil, epirubicin, and cyclophosphamide concomitant with trastuzumab. BMC cancer. 2015; 15:622.

14. Houssami N, Macaskill $P$, von Minckwitz G, Marinovich ML, Mamounas E. Meta-analysis of the association of breast cancer subtype and pathologic complete response to neoadjuvant chemotherapy. European journal of cancer. 2012; 48:3342-3354.

15. Zhou X, Zhang J, Yun H, Shi R, Wang Y, Wang W, Lagercrantz SB, Mu K. Alterations of biomarker profiles after neoadjuvant chemotherapy in breast cancer: tumor heterogeneity should be taken into consideration. Oncotarget. 2015; 6:36894-36902. doi: 10.18632/ oncotarget. 5050 .

16. Philippova M, Pfaff D, Kyriakakis E, Buechner SA, Iezzi G, Spagnoli GC, Schoenenberger AW, Erne P, Resink TJ. T-cadherin loss promotes experimental metastasis of squamous cell carcinoma. European journal of cancer. 2013; 49:2048-2058.

17. Adachi Y, Takeuchi T, Nagayama T, Ohtsuki Y, Furihata M. Zeb1-mediated T-cadherin repression increases the invasive potential of gallbladder cancer. FEBS letters. 2009; 583:430-436.

18. Takeuchi T, Liang SB, Ohtsuki Y. Downregulation of expression of a novel cadherin molecule, T-cadherin, in basal cell carcinoma of the skin. Molecular carcinogenesis. 2002; 35:173-179.

19. Mukoyama Y, Utani A, Matsui S, Zhou S, Miyachi Y, Matsuyoshi N. T-cadherin enhances cell-matrix adhesiveness by regulating betal integrin trafficking in cutaneous squamous carcinoma cells. Genes to cells: devoted to molecular \& cellular mechanisms. 2007; 12:787-796.

20. Andreeva AV, Kutuzov MA. Cadherin 13 in cancer. Genes, chromosomes \& cancer. 2010; 49:775-790.

21. Ciatto C, Bahna F, Zampieri N, VanSteenhouse HC, Katsamba PS, Ahlsen G, Harrison OJ, Brasch J, Jin X, Posy S, Vendome J, Ranscht B, Jessell TM, et al. T-cadherin structures reveal a novel adhesive binding mechanism. Nature structural \& molecular biology. 2010; 17:339-347.

22. Wang M, Kong D, Zhou Y, Wang W. Expression and predictive value of prognosis of T-cadherin in breast cancer. Chin J Oper Proc Gen Surg 2014; 8:157-160.

23. Kuphal S, Martyn AC, Pedley J, Crowther LM, Bonazzi VF, Parsons PG, Bosserhoff AK, Hayward NK, Boyle GM. $\mathrm{H}$-cadherin expression reduces invasion of malignant melanoma. Pigment cell \& melanoma research. 2009; 22:296-306.

24. Ellmann L, Joshi MB, Resink TJ, Bosserhoff AK, Kuphal S. $\mathrm{BRN} 2$ is a transcriptional repressor of CDH13 (T-cadherin) in melanoma cells. Laboratory investigation; a journal of technical methods and pathology. 2012; 92:1788-1800.

25. Makarla PB, Saboorian MH, Ashfaq R, Toyooka KO, Toyooka S, Minna JD, Gazdar AF, Schorge JO. Promoter hypermethylation profile of ovarian epithelial neoplasms. Clinical cancer research. 2005; 11:5365-5369. 
26. Hibi K, Kodera Y, Ito K, Akiyama S, Nakao A. Methylation pattern of CDH13 gene in digestive tract cancers. British journal of cancer. 2004; 91:1139-1142.

27. Tang Y, Dai Y, Huo J. Decreased expression of T-cadherin is associated with gastric cancer prognosis. Hepatogastroenterology. 2012; 59:1294-1298.

28. Kim DS, Kim MJ, Lee JY, Kim YZ, Kim EJ, Park JY. Aberrant methylation of E-cadherin and H-cadherin genes in nonsmall cell lung cancer and its relation to clinicopathologic features. Cancer. 2007; 110:2785-2792.

29. Takeuchi T, Misaki A, Chen BK, Ohtsuki Y. H-cadherin expression in breast cancer. Histopathology. 1999; 35:87-88.

30. Toyooka KO, Toyooka S, Virmani AK, Sathyanarayana UG, Euhus DM, Gilcrease M, Minna JD, Gazdar AF. Loss of expression and aberrant methylation of the CDH13 (H-cadherin) gene in breast and lung carcinomas. Cancer research. 2001; 61:4556-4560.

31. Kong DD, Yang J, Li L, Wang W, Chen YN, Wang SB, Zhou YZ. T-cadherin association with clinicopathological features and prognosis in axillary lymph node-positive breast cancer. Breast cancer research and treatment. 2015; 150:119-126.

32. Kraus JA, Beriwal S, Dabbs DJ, Ahrendt GM, McGuire KP, Johnson RR, Badve P, Puhalla SL, Bhargava R. Predictors of pathologic complete response after standard neoadjuvant chemotherapy in triple-negative breast carcinoma. Applied immunohistochemistry \& molecular morphology. 2012; 20:334-339.

33. Portier BP, Minca EC, Wang Z, Lanigan C, Gruver AM, Downs-Kelly E, Budd GT, Tubbs RR. HER4 expression status correlates with improved outcome in both neoadjuvant and adjuvant Trastuzumab treated invasive breast carcinoma. Oncotarget. 2013; 4:1662-1672. doi: 10.18632/oncotarget. 1232 .
34. Kinsella MD, Nassar A, Siddiqui MT, Cohen C. Estrogen receptor (ER), progesterone receptor (PR), and HER2 expression pre- and post- neoadjuvant chemotherapy in primary breast carcinoma: a single institutional experience. International journal of clinical and experimental pathology. 2012; 5:530-536.

35. Lee SH, Chung MA, Quddus MR, Steinhoff MM, Cady B. The effect of neoadjuvant chemotherapy on estrogen and progesterone receptor expression and hormone receptor status in breast cancer. American journal of surgery. 2003; 186:348-350.

36. Fisher ER, Wang J, Bryant J, Fisher B, Mamounas E, Wolmark N. Pathobiology of preoperative chemotherapy: findings from the National Surgical Adjuvant Breast and Bowel (NSABP) protocol B-18. Cancer. 2002; 95:681-695.

37. Cao YM, Wei CY, Huang P, Mo JY. Analysis of the impact of histopathology and molecular markers on pathological complete response to neoadjuvant chemotherapy in breast cancer. Chin J Cancer Prev Treat. 2015; 22:1479-1483.

38. Hammond ME, Hayes DF, Dowsett M, Allred DC, Hagerty KL, Badve S, Fitzgibbons PL, Francis G, Goldstein NS, Hayes M, Hicks DG, Lester S, Love R, et al. American Society of Clinical Oncology/College of American Pathologists guideline recommendations for immunohistochemical testing of estrogen and progesterone receptors in breast cancer. Archives of pathology \& laboratory medicine. 2010; 134:907-922.

39. Goldhirsch A, Wood WC, Coates AS, Gelber RD, Thurlimann B, Senn HJ, Panel m. Strategies for subtypesdealing with the diversity of breast cancer: highlights of the St. Gallen International Expert Consensus on the Primary Therapy of Early Breast Cancer 2011. Annals of oncology. 2011; 22:1736-1747. 